\title{
ABSORPTION SPECTRUM OF Ni(II) IONS DOPED IN LITHIUM SODIUM POTASSIUM SULPHATE SINGLE CRYSTAL
}

\author{
R. Rama Kumar and B.C. Venkata Reddy \\ Department of Physics, S.V. University, Tirupati - 517 502, India
}

(Received January 30, 1995)

\begin{abstract}
The optical absorption spectra of lithium sodium potassium sulphate doped $\mathrm{Ni}^{2+}$ ions at 300 and $77 \mathrm{~K}$ was recorded. The observed bands are assigned as transitions from the ground state ${ }^{3} A_{2 g}(F)$ to various excited triplet and singlet states of the $\mathrm{Ni}^{2+}$ ion in octahedral symmetry. The splittings observed for the bands ${ }^{3} T_{1 \mathrm{~g}}(F)$ and ${ }^{3} T_{2 \mathrm{~g}}(F)$ at liquid nitrogen temperature have been explained as due to spin-orbit interaction. The oscillator strengths of the transitions were computed from the area under the curves. From a detailed analysis of the bands of the spectrum, the crystal field parameters $B$, $C, D q$ and $\xi$ are evaluated.
\end{abstract}

PACS numbers: 78.40.-q, 78.50.-w

\section{Introduction}

The optical absorption spectra of $\mathrm{Ni}^{2+}$ ion in various environments have been studied extensively by several authors [1-6]. Since $\mathrm{Ni}^{2+}$ ion among the transition metal ions has strong absorption bands in the 200-1500 $\mathrm{nm}$ region, which are well assigned, $\mathrm{Ni}^{2+}$ ion was used as an impurity and optical probe to study the electronic absorption spectra in different host lattices with different symmetry ligands [7-11]. Ilowever, there seem to be no reports available in the literature on optical studies of $\mathrm{Ni}^{2+}$ ions in the lithium sodium potassium sulphate (LSPS) lattice. Hence the studies of $\mathrm{Ni}^{2+}$ ion in LSPS werc undertaken at 300 and $77 \mathrm{~K}$ to obtain the crystal field parameters and to estimate the site symmetry of the ion in the host lattice.

The triple salt, lithium sodium potassium sulphate $\left(\mathrm{Li}_{2} \mathrm{NaK}\left(\mathrm{SO}_{4}\right)_{2}\right)$ has been the subject of many investigations for the past few years [12-18]. This compound is known to crystallize in an orthorhombic system with space group $P 2{ }_{1} 2_{1} 2_{1}$ and lattice dimensions, $a=4.95, b=7.81$ and $c=19.02 \AA[16]$. 


\section{Experimental}

Single crystals of LSPS were grown by slow evaporation of saturated aqueous solution of the corresponding sulphates mixed in their equimolar ratio. The doping of $\mathrm{Ni}^{2+}$ ions was made by adding about 0.1 mole percent of nickel sulphate to the saturated solution. The crystals grown were clear and green in colour.

The optical absorption spectrum was recorded on a Cary-17D spectrophotometer both at room $(300 \mathrm{~K})$ and liquid nitrogen $(77 \mathrm{~K})$ temperatures. The oscillator strengths were computed by measuring the area under the curves of the spectra.

\section{Theory}

$\mathrm{Ni}^{2+}$ has eight $d$ electrons. The electronic states of $\mathrm{Ni}^{2+}$ in a strong octahedral field arising from the ground and the excited electronic configurations are as follows:

from the ground

$$
\left(t_{2 \mathrm{~g}}\right)^{6}\left(e_{\mathrm{g}}\right)^{2}:{ }^{3} A_{2 \mathrm{~g}},{ }^{1} A_{1 \mathrm{~g}},{ }^{1} E_{\mathrm{g}} \text {, }
$$

from the first excited

$$
\left(l_{2 \mathrm{~g}}\right)^{5}\left(e_{\mathrm{g}}\right)^{3}:{ }^{3} T_{1 \mathrm{~g}},{ }^{3} T_{2 \mathrm{~g}},{ }^{1} T_{1 \mathrm{~g}},{ }^{1} T_{2 \mathrm{~g}}
$$

from the second excited $\left(t_{2 \mathrm{~g}}\right)^{4}\left(e_{\mathrm{g}}\right)^{4}:{ }^{3} T_{1 \mathrm{~g}},{ }^{1} A_{1 \mathrm{~g}},{ }^{1} E_{\mathrm{g}},{ }^{1} T_{2 \mathrm{~g}}$.

According to IIund's rule, ${ }^{3} A_{2 \mathrm{~g}}$ lies lowest and forms the ground state of the ion. The energy expressions for all the states in the absence of spin-orbit interaction were given in the form of matrices by Tanabe and Sugano [19]. Lakshman et al. [20] presented these matrices in a linear form. In the presence of spin-orbit interaction, the energy levels are designated as $\Gamma_{1}, \Gamma_{2}, \Gamma_{3}, \Gamma_{4}$ and $\Gamma_{5}$. The energy matrices for these spin-orbit levels were presented by Liehr and Ballhausen [21] in terms of $F_{2}, F_{4}, D q$ and $\lambda$ and in terms of $B, C, D q$ and $\xi$ by Lakshman and Rao [22].

\section{Results and analysis}

The crystal shows the characteristic absorption of $\mathrm{Ni}^{2+}$ ions in the visible and near infrared regions. The optical absorption spectrum observed at room temperature is shown in Fig. 1. Five bands have been observed at room temperature, one in the near infrared at $8850 \mathrm{~cm}^{-1}$, three in the visible at 13889, 14793 (and $15060), 22222 \mathrm{~cm}^{-1}$ and one in the near ultraviolet at $26596 \mathrm{~cm}^{-1}$. Among these five bands, the band in the near ultraviolet is the most intense.

On cooling the crystal to liquid nitrogen temperature, changes in intensity and band positions are observed. The spectrum observed at liquid nitrogen temperature is shown in Fig. 2. From the spectra, it can be seen that at low temperature the band $8850 \mathrm{~cm}^{-1}$ at $300 \mathrm{~K}$, has resolved into two bands with band maxima at 9174 and $9524 \mathrm{~cm}^{-1}$, with a blue shift of $499 \mathrm{~cm}^{-1}$. The band at $14927 \mathrm{~cm}^{-1}$ has been found to split into four components with maxima at 15015, 15152, 15748 and $16026 \mathrm{~cm}^{-1}$, while the bands 13889,22222 and $26596 \mathrm{~cm}^{-1}$ are shifted to 13986 , 22831 and $27174 \mathrm{~cm}^{-1}$, respectively. 


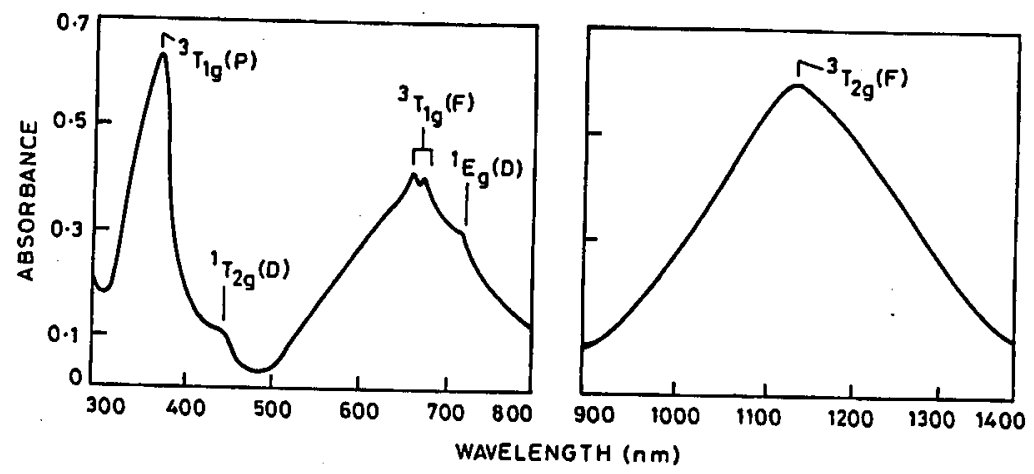

Fig. 1. Absorption spectrum of $\mathrm{Ni}^{2+}$ in lithium sodium potassium sulphate at room temperature $(300 \mathrm{~K})$.

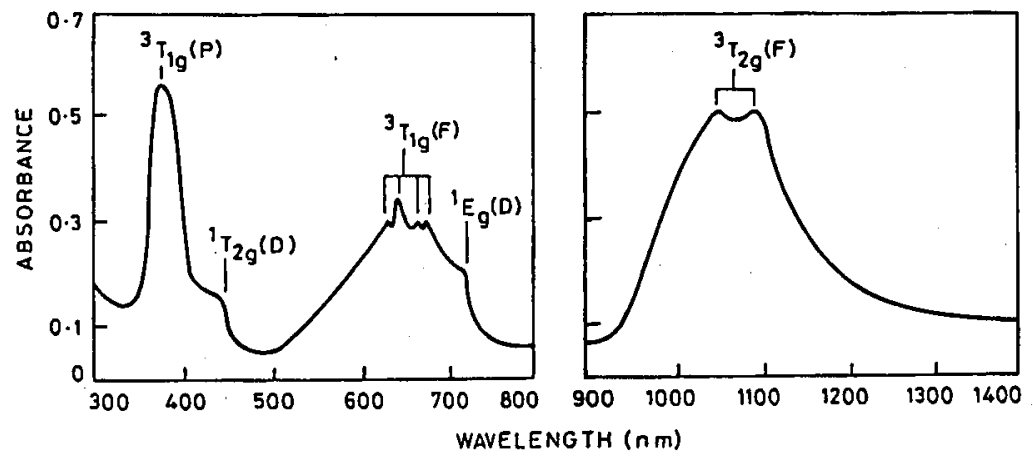

Fig. 2. Absorption spectrum of $\mathrm{Ni}^{2+}$ in lithium sodium potassium sulphate at liquid nitrogen temperature $(77 \mathrm{~K})$.

From the nature and observed position of the bands, they have been attributed to an ion of $\mathrm{Ni}^{2+}$ in octahedral symmetry. The ground state electronic configuration of the $\mathrm{Ni}^{2+}$ ion in octahedral symmetry is ${ }^{3} A_{2 \mathrm{~g}}(F)$. According to the energy level scheme, three spin-allowed bands should be observed which arise due to the transitions from the ground state to the excited states ${ }^{3} T_{2 \mathrm{~g}}(F),{ }^{3} T_{1 \mathrm{~g}}(F)$, and ${ }^{3} T_{1 \mathrm{~g}}(P)$ arranged in the order of increasing energy.

Often most of the nickel complexes show a double-peaked absorption at room temperature $[3,23]$. Indeed, in the present work also, we observed a double-peaked band separated by $267 \mathrm{~cm}^{-1}$ located at 14793 and $15060 \mathrm{~cm}^{-1}$. The intense bands observed at 8850 and $26596 \mathrm{~cm}^{-1}$ have therefore been attributed to ${ }^{3} A_{2 \mathrm{~g}}(F) \longrightarrow$ ${ }^{3} T_{2 \mathrm{~g}}(F)$ and ${ }^{3} A_{2 \mathrm{~g}}(F) \longrightarrow{ }^{3} T_{1 \mathrm{~g}}(P)$ transitions, respectively, and the double-peaked band is attributed to ${ }^{3} A_{2 \mathrm{~g}}(F) \longrightarrow{ }^{3} T_{1 \mathrm{~g}}(F)$ transition. The three 'spin-allowed bands are expected to show blue shift at low temperature, as their corresponding states ${ }^{3} T_{2 \mathrm{~g}}(F),{ }^{3} T_{1 \mathrm{~g}}(F)$ and ${ }^{3} T_{1 \mathrm{~g}}(P)$ have positive slopes in the Tanabe-Sugano energy level diagram [19], given for $d^{8}$ configuration. Therefore, the observed blue shifts for the ${ }^{3} T_{2 \mathrm{~g}}(F)$ and ${ }^{3} T_{1 \mathrm{~g}}(P)$ bands at low temperature are in accordance with 
the theory. In the present work, no such observation could be made for the ${ }^{3} T_{1 \mathrm{~g}}(F)$ band as it has been found to split on cooling the crystal to liquid nitrogen temperature. Such splittings in ${ }^{3} T_{1 \mathrm{~g}}(F)$ band have been reported in literature by several investigators $[5,6,24,25]$. This characteristic splitting of the band further supports the assignment. The double-peaked band attributed to ${ }^{3} A_{2 \mathrm{~g}}(F) \longrightarrow{ }^{3} T_{1 \mathrm{~g}}(F)$ splits into four components and the near infrared band attributed to ${ }^{3} A_{2 \mathrm{~g}}(F) \longrightarrow$ ${ }^{3} T_{2 \mathrm{~g}}(F)$ into two. Due to spin-orbit interaction, each of these bands must split into four components. But in the present investigation, the near infrared band is not properly resolved and only two components are observed. Similar features are reported for $\mathrm{Ni}^{2+}$ ions in various host lattices [24, 26].

Lever [23] noted that ${ }^{3} T_{1 \mathrm{~g}}(F)$ appears as well defined double-peaked band if $D q / B$ ratio is near unity. The calculated $D q / B$ ratio at room temperature in the present work is also nearer to unity (0.91). This also justifies the assignment of the double-peaked band to the transition from ${ }^{3} A_{2 \mathrm{~g}}(F) \longrightarrow{ }^{3} T_{1 \mathrm{~g}}(F)$.

According to the theory, some spin-forbidden triplet-to-singlet transitions may also appear and the intensity of such bands would be lower. The bands observed at 13889 and $22222 \mathrm{~cm}^{-1}$ are assigned to ${ }^{3} A_{2 \mathrm{~g}}(F) \longrightarrow{ }^{1} E_{\mathrm{g}}(D)$ and ${ }^{3} A_{2 \mathrm{~g}}(F) \longrightarrow{ }^{1} T_{2 \mathrm{~g}}(D)$ transitions, respectively. On cooling the crystal to liquid nitrogen temperature, the above two spin-forbidden bands show blue shifts as their energy levels have positive slopes in the Tanabe-Sugano energy level diagram.

\section{Discussion}

In optical studies, one important and interesting feature observed on cooling to low temperature is the splitting of some of the bands. The reason for this splitting may be spin-orbit interaction or lowering of symmetry or superposition of certain vibrational modes of radicals or ligands. If the bands are split due to lowering of symmetry, the other orbital doublet and triplet states are also expected to split into various components. This is not observed in the present work. The intensity of the splitting of the bands observed due to simultaneous electronic and vibrational transitions is very weak [1]. In the present work, the average intensity of the split bands is not weak. Therefore the nature of the splittings observed at liquid nitrogen temperature for the ${ }^{3} T_{1 \mathrm{~g}}(F)$ and ${ }^{3} T_{2 \mathrm{~g}}(F)$ bands appear to be due to the spin-orbit effect. Therefore, the ligand field calculations are carried out in terms of the octahedral field combined with spin-orbit coupling. The ${ }^{3} T_{1 \mathrm{~g}}(F)$ level splits into three $\left(\Gamma_{3}+\Gamma_{5}, \Gamma_{4}\right.$ and $\left.\Gamma_{1}\right)$ and four $\left(\Gamma_{5}, \Gamma_{3}, \Gamma_{4}\right.$ and $\left.\Gamma_{1}\right)$ component levels, respectively, in the first and second order configurational interactions. Using the free ion spin-orbit coupling parameter $\xi=600 \mathrm{~cm}^{-1}$, the calculated first order separation between the components of ${ }^{3} T_{1 \mathrm{~g}}(F)$ state would be 140 and $280 \mathrm{~cm}^{-1}$. Since the observed splittings of $137 \mathrm{~cm}^{-1}(15152-15015)$ and $278 \mathrm{~cm}^{-1}$ (16026-15748) are approximately of the same order of spin-orbit splitting expected for $\mathrm{Ni}^{2+}$ ion in the crystal, the energy matrices inclusive of spin-orbit effect are diagonalized for different values of $D q$, with $B=980 \mathrm{~cm}^{-1}, C=3280 \mathrm{~cm}^{-1}$ and $\xi=600 \mathrm{~cm}^{-1}$. The best fit of the observed bands at $77 \mathrm{~K}$ could be obtained with $D q=930 \mathrm{~cm}^{-1}$. The corresponding energy level diagram ( $E$ vs. $\left.D q\right)$ is shown in Fig. 3. The observed and calculated band maxima positions along with their oscillator strengths are presented in Table I. 


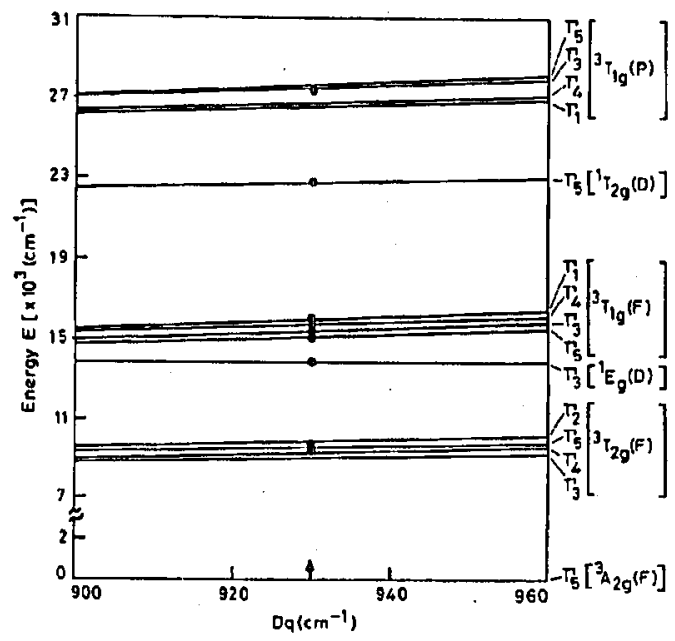

Fig. 3. Energy level diagram of $\mathrm{Ni}^{2+}$ in lithium sodium potassium sulphate in cubic environment plotted as a function of crystal field parameter $D q$, with $B=980 \mathrm{~cm}^{-1}$, $C=3280 \mathrm{~cm}^{-1}$ and $\xi=600 \mathrm{~cm}^{-1}$. The solid circles show the experimental values at $77 \mathrm{~K}$.

TABLE I

The observed and calculated energies, oscillator strengths, and assignments for the bands of $\mathrm{Ni}^{2+}$ in lithium sodium potassium sulphate $\left(B=980 \mathrm{~cm}^{-1}\right.$, $C=3280 \mathrm{~cm}^{-1}, D q=930 \mathrm{~cm}^{-1}$ and $\xi=600 \mathrm{~cm}^{-1}$ ).

\begin{tabular}{|c|c|c|c|c|c|c|}
\hline \multirow{3}{*}{$\begin{array}{c}\text { Transition } \\
\text { from } \\
{ }^{3} A_{2 g}(F)\end{array}$} & \multirow{3}{*}{$\begin{array}{c}\text { Spin-orbit } \\
\text { designation } \\
\Gamma_{5}\end{array}$} & \multicolumn{3}{|c|}{ Band positions $\left[\mathrm{cm}^{-1}\right]$} & \multirow{2}{*}{\multicolumn{2}{|c|}{$\begin{array}{c}\text { Oscillator strengths } \\
f\left(\times 10^{-5}\right)\end{array}$}} \\
\hline & & \multirow[t]{2}{*}{ Cal. } & \multicolumn{2}{|c|}{ Obs. } & & \\
\hline & & & $300 \mathrm{~K}$ & $77 \mathrm{~K}$ & $300 \mathrm{~K}$ & $77 \mathrm{~K}$ \\
\hline \multirow{4}{*}{${ }^{3} T_{2 \mathrm{~g}}(F)$} & $\Gamma_{3}$ & 9067 & 8850 & \multirow{4}{*}{$\begin{array}{l}9174 \\
9524\end{array}$} & \multirow{4}{*}{5.71} & \multirow{4}{*}{3.76} \\
\hline & $\Gamma_{4}$ & 9210 & & & & \\
\hline & $\Gamma_{5}$ & 9572 & & & & \\
\hline & $\Gamma_{2}$ & 9690 & & & & \\
\hline${ }^{1} E_{\mathrm{g}}(D)$ & $\Gamma_{3}$ & 13879 & 13889 & 13986 & - & - \\
\hline \multirow{4}{*}{${ }^{3} T_{1 \mathrm{~g}}(F)$} & $\overline{\Gamma 5}$ & 15197 & 14793 & 15015 & \multirow{4}{*}{7.31} & \multirow{4}{*}{5.41} \\
\hline & $\Gamma_{3}$ & 15411 & 15060 & 15152 & & \\
\hline & $\Gamma_{4}$ & 15739 & & 15748 & & \\
\hline & $\Gamma_{1}$ & 15907 & & 16026 & & \\
\hline${ }^{1} T_{2 \mathbf{g}}(D)$ & $\Gamma_{5}$ & 22812 & 22222 & 22831 & - & - \\
\hline \multirow{4}{*}{${ }^{3} T_{1_{\mathrm{g}}}(P)$} & $\overline{\Gamma_{1}}$ & 26658 & 26596 & \multirow{4}{*}{27174} & \multirow{4}{*}{12.2} & \multirow{4}{*}{7.22} \\
\hline & $\Gamma_{4}$ & 26720 & & & & \\
\hline & $\Gamma_{3}$ & 27593 & & & & \\
\hline & $\Gamma_{5}$ & 27693 & & & & \\
\hline
\end{tabular}

* Sum of all split components. 
When the crystal is cooled from room temperature to liquid nitrogen temperature, all the bands showed a decrease in intensity, which is characteristic of the vibronic intensity mechanism and is expected for the $d-d$ transitions of an octahedral transition metal ion complex. Similar observations were reported by Venkata Subbaiah et al. [6], Lakshman and Rao [22], McPherson and Devaney [27] and Rao et al. [28] in their absorption studies of $\mathrm{Ni}^{2+}$ complexes.

The energy parameters $(B, C$ and $D q)$ obtained in the present work are given in Table II along with the parameters reported for $\mathrm{Ni}^{2+}$ ion in various crystals. From the table it can be seen that the energy parameters evaluated in the present work are in good agreement with the values reported by several investigators for $\mathrm{Ni}^{2+}$ ion in $O_{h}$ symmetry associated with the spin-orbit interaction. This also strengthens our assignments and analysis on the basis of spin-orbit interaction.

The interelectronic repulsion parameter $B$ for free $\mathrm{Ni}^{2+}$ ion is $1080 \mathrm{~cm}^{-1}$ [33]. In the present work, we obtained a $B$ value equal to $980 \mathrm{~cm}^{-1}$ at $77 \mathrm{~K}$ and this suggests that the ionic bonding is more predominant in the complex.

TABLE II

Comparison of energy parameters of $\mathrm{Ni}^{2+}$ in LSPS with those reported for other lattices.

\begin{tabular}{l|c|c|c|c}
\hline \hline \multicolumn{1}{c|}{$\mathrm{Ni}^{2+}$ ion in } & $\begin{array}{c}B \\
{\left[\mathrm{~cm}^{-1}\right]}\end{array}$ & $\begin{array}{c}C \\
{\left[\mathrm{~cm}^{-1}\right]}\end{array}$ & $\begin{array}{c}D q \\
{\left[\mathrm{~cm}^{-1}\right]}\end{array}$ & Ref. \\
\hline $\mathrm{MgTl}_{2}\left(\mathrm{SO}_{4}\right)_{2} \cdot 6 \mathrm{H}_{2} \mathrm{O}$ & 900 & 3660 & 960 & 6 \\
$\mathrm{Cd}\left(\mathrm{NH}_{4}\right)_{2}\left(\mathrm{SO}_{4}\right)_{2} \cdot 6 \mathrm{H}_{2} \mathrm{O}$ & 955 & 4202 & 922 & 24 \\
$\mathrm{MgKPO}_{4} \cdot 6 \mathrm{H}_{2} \mathrm{O}$ & 890 & 3740 & 935 & 25 \\
$\mathrm{MgNH}_{4} \mathrm{PO}_{4} \cdot 6 \mathrm{H}_{2} \mathrm{O}$ & 910 & 3981 & 915 & 26 \\
$\mathrm{ZnTl}_{2}\left(\mathrm{SO}_{4}\right)_{2} \cdot 6 \mathrm{H}_{2} \mathrm{O}$ & 905 & 3420 & 950 & 28 \\
$\mathrm{LiCsSO}_{4}$ & 890 & 3600 & 950 & 29 \\
$\mathrm{NaNH}_{4} \mathrm{SO}_{4} \cdot 2 \mathrm{H}_{2} \mathrm{O}$ & 740 & 3160 & 1000 & 30 \\
$\mathrm{LiGa}_{5} \mathrm{O}_{8}$ & 928 & 3073 & 977 & 31 \\
$\mathrm{~K}_{2} \mathrm{Zn}\left(\mathrm{SO}_{4}\right)_{2} \cdot 6 \mathrm{H}_{2} \mathrm{O}$ & 944 & 3411 & 941 & 31 \\
$\mathrm{CdK}_{2}\left(\mathrm{SO}_{4}\right)_{2} \cdot 6 \mathrm{H}_{2} \mathrm{O}$ & 940 & 3760 & 937 & 32 \\
$\mathrm{Li}_{2} \mathrm{NaK}_{2}\left(\mathrm{SO}_{4}\right)_{2}$ & 980 & 3280 & 930 & present work
\end{tabular}

\section{Conclusions}

The optical absorption spectra of LSPS: $\mathrm{Ni}^{2+}$ lattice has been studied at 300 and $77 \mathrm{~K}$. From the result and discussion, the transitions of $\mathrm{Ni}^{2+}$ in LSPS lattice were assigned and from the analysis of the spectra, the crystal field $(D q)$, Racah $(B$ and $C$ ) and spin-orbit interaction $(\xi)$ parameters were evaluated.

Basing on the results and analysis of this investigation, it is reasonable to assume that the spectrum is characteristic of $\mathrm{Ni}^{2+}$ ion in octahedral site symmetry associated with spin-orbit interaction.

The authors are thankful to Dr. K.V. Reddy, Hyderabad, for giving permission to record the absorption spectra on a Cary-17D spectrophotometer. The work reported in this paper has been financially supported by CSIR, New Delhi. 


\section{References}

[1] T.S. Piper, N. Koertge, J. Chem. Phys. 32, 559 (1960).

[2] J. Ferguson, H.J. Guggenheim, H. Kamimura, Y. Tanabe, J. Chem. Phys. 42, 775 (1965).

[3] E.I. Solomon, C.J. Ballhausen, Mol. Phys. 29, 279 (1975).

[4] D.R. Rosseinsky, I.A. Dorrity, Coord. Chem. Rev. 25, 31 (1978).

[5] B. Ghosh, R.K. Mukherjee, Phys. Status Solidi B 102, 189 (1980).

[6] A. Venkata Subbaiah, J. Lakshmana Rao, R. Murali Krishna, S.V.J. Lakshman, Z. Nat.forsch. A 47, 813 (1992).

[7] W. Low, Phys. Rev. 109, 247 (1958).

[8] H. Hartmann, H. Muller, Disc. Farad. Soc. 26, 49 (1958).

[9] O.G. Holmes, D.S. McClure, J. Chem. Phys. 26, 1686 (1957).

[10] A.S. Chakravarty, R. Chatterjee, Ind. J. Phys. 35, 643 (1961).

[11] D.S. McClure, J. Phys. Chem. Solids 3, 311 (1957).

[12] I.N. Lepeshkov, N.V. Bodaleva, L.T. Kotava, Zh. Neorg. Khim. 3, 2781 (1958).

[13] I.N. Lepeshkov, N.V. Bodaleva, L.T. Kotava, Russ. J. Inorg. Chem. 6, 864 (1961).

[14] K. Kitahama, R. Frech, J. Chem. Phys. 82, 720 (1985).

[15] K. Kitahama, R. Frech, Solid State Ion. 21, 63 (1986).

[16] M.J. Heeg, A. Hurd, Acta Crystallogr. C 43, 161 (1987).

[17] J.K. Liang, X.T. Xu, Z. Chai, J. Solid State Chem. 76, 270 (1988).

[18] R. Rama Kumar, B.C. Venkata Reddy, Cryst. Res. Technol. 28, 535 (1993).

[19] Y. Tanabe, S. Sugano, J. Phys. Soc. Japan 9, 753 (1954).

[20] S.V.J. Lakshman, J. Lakshmana Rao, Ind. J. Pure Appl. Phys. 10, 497 (1972).

[21] A.D. Liehr, C.J. Ballhausen, Ann. Phys. (USA) 6, 134 (1959).

[22] S.V.J. Lakshman, J. Lakshmana Rao, Spectrochim. Acta A 35, 703 (1979).

[23] A.B.P. Lever, Inorganic Electronic Spectroscopy, 2nd ed., Elsevier, Amsterdam 1984, p. 507.

[24] P. Sathyasainath Prasad, S. Radhakrishna, Solid State Commun. 64, 561 (1987).

[25] P. Sivaprasad, K. Ramesh, Y.P. Reddy, Solid Stale Commun. 73, 239 (1990).

[26] B.V.R. Chowdari, Y. Ravisekhar, C. Muralikrishna, Phys. Status Solidi B 109, 315 (1982).

[27] G.L. McPhersion, K.O. Devaney, Inorg. Chem. 16, 1565 (1977).

[28] J.L. Rao, M.R. Reddy, S.V.J. Lakshman, Phys. Stalus Solidi B 151, 599 (1989).

[29] B.C. Venkata Reddy, B. Munibhadraiah, Ind. J. Pure Appl. Phys. 24, 577 (1986).

[30] S.V.J. Lakshman, T.V. Krishna Rao, Pramana 20, 137 (1983).

[31] D.T. Sviridov, S.D. Sviridov, Zh. Prikl. Spektrosk. 49, 851 (1988).

[32] P. Sathyasainath Prasad, S. Radhakrishna, Cryst. Latt. Def. Amorph. Mater. 14, 85 (1987).

[33] B.N. Figgis, Introduction to Ligand Fields, Interscience, New York 1966, p. 52. 